\title{
Становление студенческого спорта в России
}

\author{
Шарапова А.В. *, Ворожко Ю.В. \\ Сибирский государственный университет физической культуры и спорта, \\ 2. Омск, Россия \\ ORCID oooo-ooo1-6271-9764 sharapova_alina@icloud.com \\ ORCID oooo-Ooo3-2261-716XVorozhko51@yandex.ru
}

\begin{abstract}
Аннотация: Студенческий спорт в России имеет более чем вековую историю развития. Его зарождение происходило в начале XX века. Ссовременный этап становления студенческого спорта, начавшийся в связи с периодом реформирования общественных устоев, характеризуется появлением новых задач физического воспитания в высшей школе, направленных не только на развитие физических способностей студентов, но и на стимулирование их интереса к занятиям физической культурой и спортом, формирование ценностей здорового образа жизни, в которых двигательная активность является необходимым условием. Mamepuaлъ. Анализ выступлений сборной команды Омской области в студенческих соревнованиях различного уровня с 2014 по 2019 гг. Memoды исследованшя. Анализ научной литературы и Интернет-источников, ретроспективный анализ, методы математической статистики.Резулътатъ.Проанализированыструктура тренировочного процесса студенток, занимающихся художественной гимнастикой, а также результаты их выступлений на студенческих соревнованиях различного уровня.

Ключевые слова: студенческий спорт, физическая культура, становление, гимнастика, Универсиада.
\end{abstract}

Для цитирования: Шарапова А.В.*, Ворожко Ю.В. Становление студенческого спорта в России. Педагогико-психологические и медико-биологические проблемы физической культуры и спорта. 2020; 15(4): 44-49. DOI: 10.14526/2070-4798-2020-15-4-44-49

\section{Student sport formation in Russia}

\author{
Alina V.Sharapova*, Yurij V. Vorozhko \\ Siberian State University of Physical Culture and Sport, \\ Omsk, Russia \\ ORCID oooo-ooo1-6271-9764 sharapova_alina@icloud.com* \\ ORCID oooo-ooo3-2261-716XVorozhko51@yandex.ru
}

\begin{abstract}
Student sport in Russia has more than one century history of development. Its formation started at the beginning of the XX century. Modern stage of student sport formation, which started in terms of social basis reformation period, is characterized by new objectives of physical upbringing at higher school, directed not only toward students' physical abilities development, but also toward their interest in physical culture and sport lessons stimulation, a healthy life style values formation, where motor activity is a necessary condition. Materials. Analyzing the performances of the national team of Omsk region at student competitions of different levels since 2014 till 2019. Research methods. Information sources and Internet-sources analysis, retrospective analysis, methods of mathematical statistics. Results. The structures of the training process were analyzed among female students, who go in for calisthenics. The results of their performances at student competitions of different level were analyzed.

Keywords: student sport, physical culture, formation, gymnastics, Universiade.
\end{abstract}

For citation: Alina V. Sharapova*, Yurij V. Vorozhko. Student sport formation in Russia. Russian Journal of Physical Education and Sport. 2020; 15(4): 44-49. DOI: 10.14526/2070-4798-2020-15-4-44-49

\section{ВВЕДЕНИЕ}

С 1994 года в России проводятся

массовые соревнования для студентов - чемпионаты России. Предстоящие и настоящие преобразования привлекают все больше студентов к занятиям физической культурой и 
спортом, а это, в свою очередь, приводит к росту мастерства и новым победам наших студентовспортсменов на соревнованиях $[1,2,3]$.

Также с 1905 года проводятся Универсиады - международные и национальные спортивные соревнования среди студентов. Название «Универсиада» происходит от слов «Университет» и «Олимпиада». Данный вид соревнований часто упоминается как Всемирные студенческиеигры и Всемирныеуниверситетские игры. Каждые два года проводятся летние и зимние универсиады $[4,5,6,7]$.

История студенческого спорта началась в 1905 году, когда в США прошли первые международные соревнования среди студентов. В 1919 году Жаном Птижаном была создана Конфедерация студентов. Под эгидой этой организации в 1923 году состоялись первые Всемирные университетские игры в Париже [2, c.2].

Все участники соревнований должны удовлетворять следующим требованиям:

а) быть гражданином страны, которую они представляют;

б) быть не моложе 17 и не старше 28 лет на 1 января года проведения соревнований;

в) быть действующим студентом высшего учебного заведения либо окончить вуз не ранее 1 года до начала универсиады [8,9,10].

В высших учебных заведениях России культивируется более 60 видов спорта, наиболее массовыми из них являются художественная гимнастика, бадминтон, баскетбол, бокс, лыжный спорт, легкая атлетика, плавание, футбол и т.д.

Особой п популярностью пользуется художественная гимнастика. Российские гимнастки занимают высокие места на международной арене.

Главные качества гимнастки - это сила воли, выносливость, терпение и пластика. Выступление гимнасток всегда напоминает постановочное шоу. Во-первых, под выполнение упражнений подбирается соответствующая музыкальная композиция. Во-вторых, все упражнения выполняются под ритм музыки, что напоминает танцевальное выступление.
В-третьих, гибкость, ловкость и грация, с которой гимнастки выступают на сцене, захватывают и увлекают до последней секунды представления.

За всей красотой и шармом номеров гимнасток скрывается ежедневная и многочасовая работа в зале. Профессиональные занятия гимнастикой предполагают длительные двигательные тренировки и активную нагрузку на мышцы. Многократное повторение движений в комплексе со строгой дисциплинированностью - это основные требования на пути к успеху.

Обычно тренировки проходят с обеда до вечера. В них входит хореография, разминка, групповые и индивидуальные упражнения с предметами, ОФП.

Хореографическая подготовка в художественнойгимнастикеважна, отнеезависит танцевальность, эффектность выступления в целом. Во время обучения хореографии вырабатываются правильная осанка, мимика и выразительность. Хореографическая подготовка играет и образовательную роль. Она проходит минимум 5 раз в неделю, по 1 часу в день.

Разминка состоит из комплекса упражнений. Постепенно разогревая мышцы, организм готовится к нагрузке. Благодаря разминке разогреваются мышцы, связки и сухожилия, что улучшает их эластичность и снижает риск возникновения травм и растяжений. Разминка также помогает улучшить кровообращение в организме, что способствует насыщению мышц кислородом и питательными веществами. Это помогает повысить выносливость.

В разминку входят махи, желательно с утяжелителями, чтобы на упражнении элементы было легче выполнять, а также широкие прыжки, чтобы подготовить стопы. Прыжок воспринимается как сильное отталкивание от поверхности и набор достаточной высоты для проведения телодвижений или движений c предметом.

После разминки выполняются групповые и индивидуальные упражнения с предметами.

Во внесоревновательные дни тренировки менее интенсивные в сравнении с соревновательными, проводится по 5 чистых 
прогонов одного и другого вида.

Далее следует общая физическая подготовка (ОФП) и прыжки на скакалках. ОФП предполагает развитие основных двигательных навыков человека и его физических качеств: силы, быстроты, выносливости, ловкости, гибкости. Прыжки на скакалках способствуют развитию выносливости, прыгучести, укрепляют мышцы ног и, самое главное, помогают избавиться от лишнего веса. Лишний вес является одной из главных проблем гимнасток. Им необходимо следить за своим питанием, ежедневно взвешиваться (утром и вечером). Гимнастка, претендующая на высокие награды, должна обладать идеальной фигурой. Это поможет ей не только обратить на себя внимание судей, но и качественно выполнять большинство упражнений. Гимнастки с небольшим весом и тонкой фигурой имеют преимущество. Это помогает им без ошибок выполнять упражнения и получать высокие баллы. Вес, который оптимален для гимнастки, подсказывает тренер. Он учитывает ее телосложение, все объемы и нагрузку. Рассчитывая идеальный вес для девочки, необходимо знать ее рост. Нормы, рассчитанные для выступающих спортсменок, помогают приблизиться к победе.

В конце каждой тренировки проводятся восстановительные процедуры: массаж, йога, отвлекающие мероприятия (прогулки и др).

В соревновательные дни тренировки начинаются утром и продолжаются до вечера. Идет усиленная подготовка. Проводится уже не по 5 чистых прогонов каждого вида, а по 10 чистых. На наш взгляд, в групповом выступлении участвовать сложнее, чем выступать в личном. В групповом выступлении спортсменки должны работать в команде и чувствовать своих партнерш. На гимнастках, выступающих в группе, лежит огромная ответственность, ведь они отвечают не только за себя, но и за всю команду, в то время как в личных упражнениях небольшая помарка может быть простительна. Во время выступления в группе судьи обращают внимание не только на сложность элементов, но и на синхронность их выполнения.

Перед выступлением спортсменки поддерживают друг друга («Не получается здесь, получится на площадке»), ведь главное перед выступлением - это настрой, потому что, если один человек переживает или нервничает, то это передается всей команде. Перед выходом гимнастки становятся в круг, говорят друг другу нужные слова, настаиваются и уверенно выходят на выступление.

Тренировочные нагрузки оказывают на спортсменок как положительное, так и отрицательное воздействие. С одной стороны, укрепляются все мышцы организма, улучшается координация движений, формируется волевой характер, повышается тонус организма, формируется красивая осанка, развивается чувство темпа и ритма, улучшается общее настроение и самочувствие. С другой стороны, профессиональные занятия провоцируют заболевания спины; постоянная работа мышцами, требующая совершенствовать растяжку, вызывает боли в мышцах и суставах; необходимость соблюдения строгой диеты для многих спортсменок представляет серьезные трудности; профессиональные занятия художественной гимнастикой требуют больших временных затрат. 
Таблица 1 - Количество медалей по художественной гимнастике на крупных соревнованиях

\begin{tabular}{|c|c|c|c|c|c|c|}
\hline $\begin{array}{l}\text { Олимпийские } \\
\text { игры (Россия) }\end{array}$ & $\begin{array}{c}1996 \text { г. - } \\
\text { Атланта } \\
1 \text { серебряная } \\
1 \text { золотая }\end{array}$ & $\begin{array}{c}200 о \text { г. - } \\
\text { Сидней } \\
2 \text { золотые } \\
1 \text { бронзовая }\end{array}$ & $\begin{array}{c}2004 \text { г. - } \\
\text { Афины } \\
2 \text { золотые } \\
1 \text { серебряная }\end{array}$ & $\begin{array}{c}2008 \text { г. - } \\
\text { Пекин } \\
2 \text { золотые }\end{array}$ & $\begin{array}{c}2012 \text { г. - } \\
\text { Лондон } \\
2 \text { золотые } \\
1 \text { серебряная }\end{array}$ & $\begin{array}{c}2016 \text { г. - Рио- } \\
\text { де-Жанейро } \\
2 \text { золотые } \\
1 \text { серебряная }\end{array}$ \\
\hline $\begin{array}{c}\text { Чемпионат } \\
\text { мира }\end{array}$ & $\begin{array}{c}1996 \text { г. } \\
1 \text { золотая } \\
4 \text { серебряных }\end{array}$ & $\begin{array}{c}1997 \text { г. } \\
4 \text { золотых } \\
4 \text { серебряных } \\
2 \text { бронзовых }\end{array}$ & $\begin{array}{c}1999 \text { г. } \\
5 \text { золотых } \\
3 \text { серебряных } \\
3 \text { бронзовых }\end{array}$ & $\begin{array}{c}2015 \text { г. } \\
8 \text { золотых } \\
6 \text { серебряных }\end{array}$ & $\begin{array}{c}2017 \text { г. } \\
7 \text { золотых } \\
5 \text { серебряных } \\
1 \text { бронзовая }\end{array}$ & $\begin{array}{c}2019 \text { г. } \\
8 \text { золотых } \\
2 \text { серебряных } \\
3 \text { бронзовых }\end{array}$ \\
\hline $\begin{array}{c}\text { Чемпионат } \\
\text { Европы }\end{array}$ & $\begin{array}{c}1978 \text { г. } \\
5 \text { золотых }\end{array}$ & $\begin{array}{c}\text { 1982г. } \\
8 \text { золотых } \\
4 \text { серебряных } \\
4 \text { бронзовых }\end{array}$ & $\begin{array}{c}\text { 20о6г. } \\
9 \text { золотых } \\
1 \text { серебряная }\end{array}$ & $\begin{array}{c}2010 г . \\
9 \text { золотых } \\
1 \text { серебряная }\end{array}$ & $\begin{array}{c}\text { 2015г. } \\
6 \text { золотых } \\
2 \text { серебряных }\end{array}$ & $\begin{array}{c}\text { 2019г. } \\
8 \text { золотых } \\
3 \text { серебряных }\end{array}$ \\
\hline
\end{tabular}

Всех этих олимпийских чемпионок, чемпионок мира и Европы подготовила советский и российский тренер, педагог, президент Всероссийской федерации Ирина Александровна Винер-Усманова. Самой известной ее воспитанницей является Алина Кабаева. Она тренировалась у Ирины ВинерУсмановой с 1995 года, в 2000 году на ОИ в Афинах завоевала бронзу, а в 2004 году на Олимпиаде в Афинах - золотую медаль в многоборье.

Тренировочный процесс перед соревнованиями в сборной России достаточно жесткий. Ирина Винер очень требовательный тренер, считающий, что все дети талантливы, главное - найти хорошего учителя, профессионала своего дела, способного раскрыть потенциал ребенка. Таких людей мало, большинство тренеров работают строго по графику, не задерживаясь лишний раз допоздна. Ирина Винер работает на результат. Занимаясь любимым делом, она забывает о времени и собственном комфорте. Требовательный тренер никогда не хвалит своих подопечных просто так - её похвалу необходимо заслужить. Но даже когда она разговаривает с юными гимнастами строго, на нее никто не обижается. Дети хорошо чувствуют, кто их любит и желает им добра.

«Спортсмен является чемпионом только в тот момент, когда стоит на пьедестале. Как только он с него спускается, снова становится просто спортсменом, которому нужно много работать, чтобы добиться новых побед. Это относится и к моей профессии - ты тренер чемпиона только тогда, когда спортсмен стоит на пьедестале», считает Ирина Винер.

В последние годы также начинает развиваться мужская художественная гимнастика. И. Винер-Усманова говорит, что все больше мужчин стало появляться в этом виде спорта. Они пока не выступают на чемпионате мира, однако в перспективе это возможно.

\section{ЗАКЛЮЧЕНИЕ}

Проанализировав представленные диаграммы, можно сделать вывод, что результаты Омской школы художественной гимнастики стабильно растут, причем в последние три года улучшились существенно. Значительный вклад в эти достижения внесла и наша команда. 
Педагогико-психологические и медико-биологические проблемы физической культуры и спорта Toм 15 № 42020

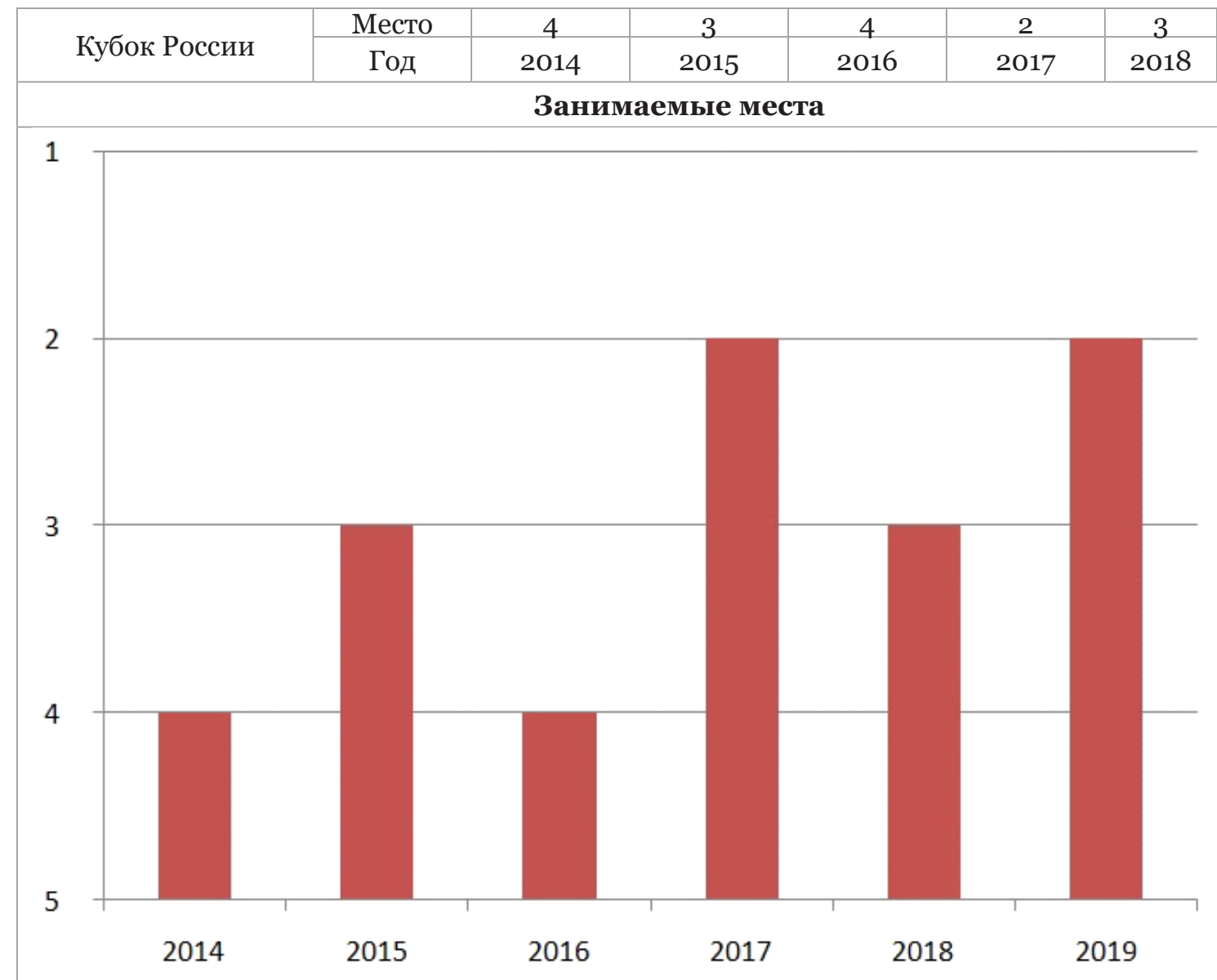

Рисунок 1 - Результаты сборной команды Омской области в групповых упражнениях с 2014 по 2019 год (занимаемые места сборной команды Омской области на Кубке России)

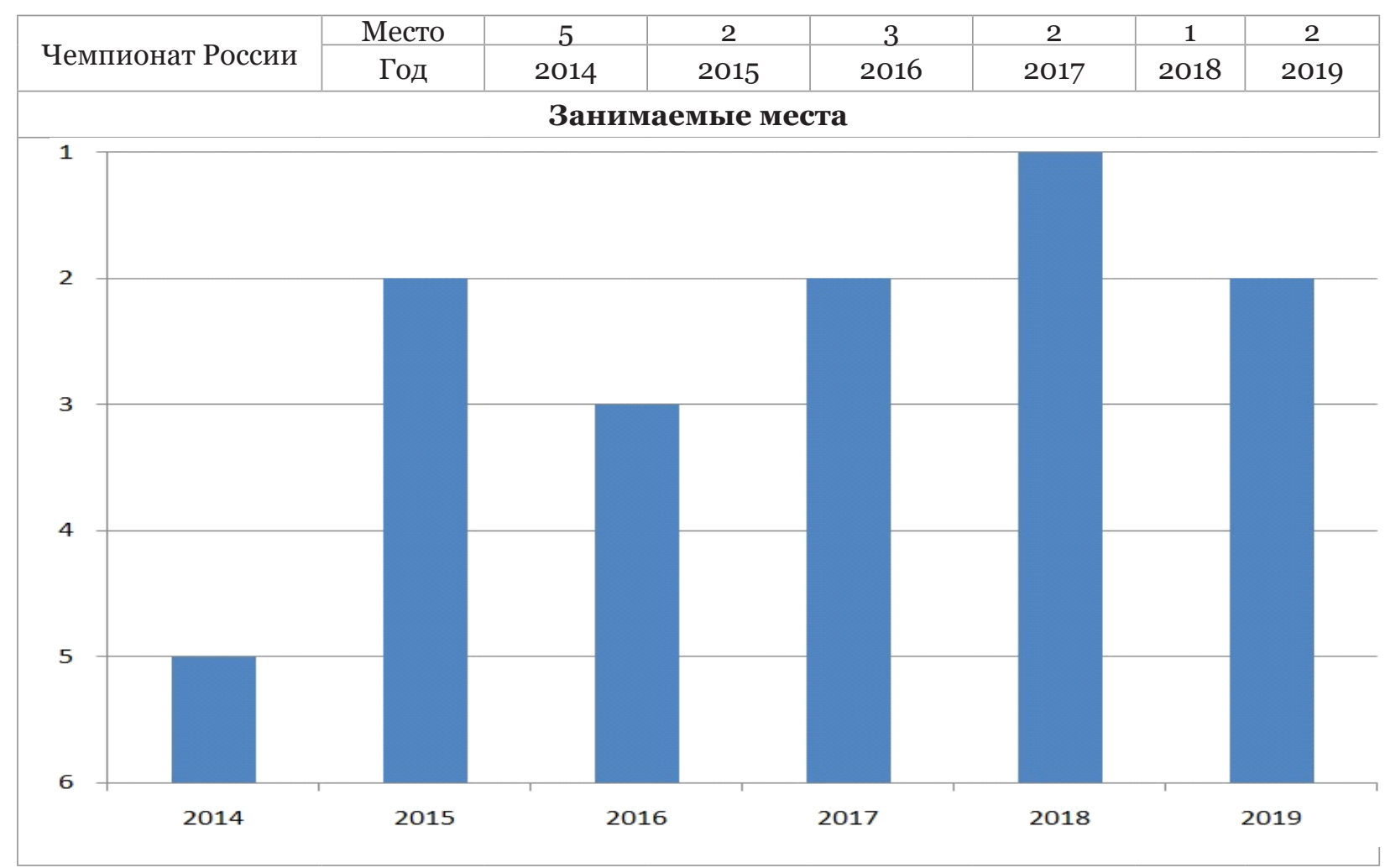

Рисунок 2 - Занимаемые места сборной команды Омской области на чемпионатах России 


\section{СПИСОК ЛИТЕРАТУРЫ}

1. Павлов И.Б., Баршая В.М. Гимнастика с методикой преподавания. Брянск : Издательство БГУ. 2005: 124.

2. Журова И.А. Российский студенческий спорт на современном этапе u его реформы. URL: http://cyberleninka.ru/ article/n/rossiyskiy-studencheskiy-sport-nasovremennometape-i-ego-reformy.

3. Ильинич В.И. Студенческий спорт и жизнь. М.: АО Аспект пресс. 2000: 448.

4. Холодов Ж.К., Кузнецов В.С. Теория и методика физического воспитания и спорта.

М.: Издательский центр «Академия». 2000: 480.

5. Шаулин В.Н. Развивающее обучение на материале физической культуры. Физкультура и спорт. 1994; 3: 8-13.

$6 . \quad$ Biddle S.J.H., Atkin A., Cavill N., Foster C. Correlates of physical activity and parenthood. Preventive Medicine. 2008; 46(2): 99-110.

$7 . \quad$ Brehm W., Wahner P., Sygusch R., Hahn U., Janke A. Health Promotion by means of Health Sport. A framework and a controlled intervention study with sedentary adults. Scandinavian Journal of Medicine and Science in Sports. 2005; 15(1): 1320.

8. Cavill N., Bauman A. Changing the way people think about health-enhancing physical activity: Do mass media campaigns have a role? Journal of Sports Sciences. 2004; 22(8): 771-790

9. Kuznetsova Z.M., Ryabchuk A.V., Labeschenkov O.V. Theoretical an d practical aspects of engineering pro file students airborne training individualization. Pedagogiko-psihologicheskie I medico-biologicheskie problemy fizicheskoj kul'tury I sporta = The Russian Journal of Physical Education and Sport, 2018; 3(2), 198-206. DOI: 10.14526/02_2018_326

10. Aleksandr S. Kuznetsov, Zinaida M. Kuznetsova. The second Congress of the members of "Russian professors meeting" social organization. Pedagogiko-psihologicheskie I medicobiologicheskie problemy fizicheskoj kul'tury I sporta $=$ The Russian Journal of Physical Education and Sport. 2020; 14(4): 5-7. DOI: 10.14526/2070-47982019-14-4-5-7

\section{Статья поступила в редакциию: 26.10.2020}

Шарапова Алина Витальевна - студент, Сибирский государственный университет физической культуры и спорта, 6440о9, Россия, г. Омск, ул. Масленникова, дом 144, е-таil: sharapova alina@icloud.ru

Ворожко Юрий Викторович - кандидат исторических наук, доцент, Сибирский государственный университет физической культуры и спорта, 6440о9, Россия, г. Омск, ул. Масленникова, дом 144, e-mail: Vorozhko51@yandex.ru 